Original Paper http://ajol.info/index.php/ijbcs http://indexmedicus.afro.who.int

\title{
Effet des herbicides à base de glyphosate et fluroxypyr sur les adventices les plus fréquentes dans la culture de l'hévéa (Hevea brasiliensis (H.B.K) (Muell. Arg) à Batouri, Nord du Gabon
}

\author{
Paul ONDO OVONO ${ }^{1 *}$, Préccilia Karène ADA OLLOMO ${ }^{1}$, \\ Samson Daudet MEDZA MVE ${ }^{1}$, Claire KEVERS ${ }^{2}$ et Jacques DOMMES ${ }^{2}$
}

\author{
${ }^{1}$ Université des Sciences et Techniques de Masuku. Unité de Recherche en Agrobiologie. Institut National \\ Supérieur d'Agronomie et de Biotechnologies. Laboratoire de biodiversité, B.P. 941 Franceville Gabon. \\ ${ }^{2}$ Plant Molecular Biology and Biotechnology Unit, B-22, University of Liège, Sart Tilman, Chemin de la Vallée \\ 4, 4000 Liège, Belgique. \\ *Auteur correspondant ; E-mail : ovonofils@gmail.com; Tel : + 241072370 61/+241 07779212.
}

\section{RESUME}

L'entretien de la culture d'hévéa est une contrainte pour Olam Rubber pour une meilleure exploitation des arbres. La présente étude vise à évaluer l'efficacité de deux herbicides à base de glyphosate et fluroxypyr sur les adventices les plus fréquents dans la culture d'hévéa à Batouri au Gabon. L'essai était composé de trois blocs d'interlignes, répartis sur trois sites et comportant 16 placettes chacun. Au total, 15 traitements chimiques (T1 à T15) ont été comparés à un traitement manuel (T0) avec trois répétitions. L'impact de ces traitements sur les adventices a été mesuré par la fréquence de présence des espèces, le temps d'exécution des désherbages, les temps de fanaison, jaunissement, sénescence et sur la rémanence en fonction des traitements, des doses et des sites de culture. Les résultats montrent que l'inventaire floristique a permis de recenser 42 espèces réparties en 33 genres et 20 familles dont 8 espèces sont les plus fréquentes sur les sites. La réaction des adventices aux traitements a varié d'une espèce à l'autre. Le temps moyen pour exécuter le désherbage chimique (21,63 minutes) est inférieur à celui nécessaire pour le désherbage manuel (36,57 minutes). Des différences hautement significatives au seuil de $5 \%(\mathrm{P}<0,0001)$ ont été observées au niveau des traitements et les doses sur tous les paramètres physiologiques mesurés. Au niveau des sites, des différences hautement significatives $(\mathrm{P}<0,0001)$ ont été également observées sur les temps de fanaison et de sénescence $(\mathrm{P}<0,0001)$ contrairement au temps de jaunissement $(\mathrm{P}<0,059)$ et à la rémanence $(\mathrm{P}<0,189)$. Toutefois, les traitements les plus efficaces ont été $\mathrm{T} 6(50$ $\mathrm{ml}$ glyphosate et $75 \mathrm{ml}$ de fluroxypyr), T10 (150 ml glyphosate et $25 \mathrm{ml}$ de fluroxypyr) et T12 (150 ml glyphosate et $75 \mathrm{ml}$ de fluroxypyr). Afin d'optimiser la sénescence et la rémanence des produits herbicides, nous recommandons à Olam Rubber Bitam, pour une lutte efficace contre les mauvaises herbes présentes sur le site, l'association de la forte dose du Fluroxypyr $(75 \mathrm{ml})$ avec la faible dose du Glyphosate $(50 \mathrm{ml})$.

() 2019 International Formulae Group. All rights reserved.

Mots clés : Hevea brasiliensis, adventices, glyphosate, fluroxypyr, Gabon. 


\title{
Effect of glyphosate and fluroxypyr herbicides on the most common weeds in the rubber crop Hevea brasiliensis (H.B.K) (Muell. Arg) in Batouri, northern Gabon
}

\begin{abstract}
The maintenance of rubber cultivation is a constraint to Olam Rubber, for a better exploitation of trees. The present study aims to evaluate the efficacy of two herbicides based on glyphosate and fluroxypyr on the most frequent weeds in the rubber crop in Batouri, Gabon. The trial consisted of three inter-row blocks, spread over three sites and 16 plots each. In total, 15 chemical treatments (T1 to T15) were compared to manual treatment (T0) with three replicates. The impact of these treatments on the weeds was measured by the frequency of presence of the species, the execution time of weeding, the times of withering, yellowing, senescence and the persistence according to the treatments the doses and the site of culture. The results show that the floristic inventory made it possible to identify 42 species divided into 33 genera and 20 families, of which 8 species are frequent on the site. The response of weeds to treatments varied from one species to another. The average time to perform chemical weeding (21.63 minutes) is less than that required for manual weeding (36.57 minutes). Highly significant differences at $5 \%(\mathrm{P}<0.001)$ were observed at the level of treatments and doses at all physiological parameters measured. At the site level, highly significant differences $(\mathrm{P}<0.0001)$ in contrast to yellowing time $(\mathrm{P}<0.059)$ and remanence $(\mathrm{P}<0.189)$. However, the most effective treatments were T6 $(150 \mathrm{ml}$ glyphosate and $75 \mathrm{ml}$ fluroxypyr). In order to optimize the senescence and persitence of the herbicide, we recommend to OlamRubber Bitam, for effective weed control on the site, the combination of the high rate of Fluroxypyr $(75 \mathrm{ml})$ with the low rate Glyphosate $(50 \mathrm{ml})$ in broad spectrum weeds control in young rubber tree.
\end{abstract}

(C) 2019 International Formulae Group. All rights reserved.

Keywords: Hevea brasiliensis, adventitious, glyphosate, fluroxypyr, Gabon.

\section{INTRODUCTION.}

L'hévéa (Hevea brasiiensis) a été introduit industriellement au Gabon par la société nationale HEVEGAB qui deviendra, après privatisation la Société d'Investissement pour l'Agriculture au Gabon SIAT Gabon (Ndoutoumou, 2007). Avec une production annuelle de 22.000 tonnes de caoutchouc sec, la production du Gabon reste en dessous de nombreux pays africains comme la Côte d'Ivoire avec 143000 tonnes et le Cameroun avec 40100 tonnes (FAO, 2009). La culture industrielle de l'hévéa connait une vive convoitise dans le monde. En 2012, le groupe singapourien Olam Rubber et le gouvernement Gabonais ont conclu un accord prévoyant un investissement de 91,5 milliards de francs CFA soit 183 millions de dollars, dans le développement d'une plantation d'hévéa et la construction d'une usine de transformation à Bitam. La plantation a démarré en 2013 dans la zone de Batouri, sur une superficie de 28000 hectares qui sera portée à 50000 hectares dans la seconde phase (Ondo et al., 2018). L'expansion agricole a pris une importance telle que les maladies et la gestion des mauvaises herbes sont devenues particulièrement préoccupantes sur le site de Batouri.

Les mauvaises herbes constituent l'une des principales contraintes biotiques qui affectent la production des systèmes de cultures, notamment dans les pays en voie de développement (Bello et al., 2013). En Afrique de l'Ouest et du Centre, plusieurs études ont été faites sur les mauvaises herbes de différentes cultures. Ce sont entre autres: les adventices de l'hévéa, de la canne à sucre, le haricot, du coton, du riz, de l'igname, des bananiers et de l'ananas (Bakayoko et al., 2016 ; Sylla et al., 2017 ; Ka et al., 2019). En effet, c'est en zone tropicale que l'estimation des pertes est la plus élevée. Les mauvaises herbes sont responsables de 40 à $60 \%$ des pertes de rendement des cultures alimentaires tropicales (Cirad, 2001). Les adventices ont un effet négatif direct par compétition avec la culture vis-à-vis des éléments nécessaires à la croissance : eau, nutriments, lumière, espace de développement (Kâ et al., 2019). La connaissance de la biologie et de l'écologie des espèces végétales infestant une culture est 
nécessaire pour l'élaboration de moyens de lutte performants. Initialement, le désherbage s'effectuait manuellement, puis progressivement, il s'est fait de manière mécanique ou thermique, puis chimique. Cette étude, à l'image de celle de Ouattara et al. (2016), peut contribuer à une meilleure connaissance de la flore et de végétation des parcelles sur le site.

Depuis son implantation en juillet 2012, 3570 ha de plantation et 32,48 ha de pépinière ont été mis en place sur le site de Batouri. L'entretien des parcelles immatures au moyen du désherbage manuel devient dense et pénible surtout en période de «planting »: pénurie de main- d'œuvre. De plus, le désherbage manuel est difficile à réaliser à cause de la durée relativement élevée du temps de travail qui requiert 250 à 700 jours/hommes par hectare (Aubry et Dounias, 2006). Les agriculteurs sont alors confrontés à l'utilisation des désherbants chimiques.

L'usage des herbicides est devenu une importante alternative à la main d'œuvre agricole. Olam est obligé de recourir aux herbicides disponibles pour essayer de remédier à cette situation. Quelques essais d'herbicides ont déjà été réalisés mais les résultats ne sont pas satisfaisants en fonction des espèces de mauvaises herbes et selon les doses (Ada, 2014; Tchuemguia, 2017). Plusieurs hypothèses ont été émises parmi lesquelles, le problème du choix des produits chimiques, des quantités d'herbicide à appliquer et la méconnaissance de la flore existante dans les plantations d'hévéa. D'où la nécessité de trouver des combinaisons possibles de produits herbicides et des doses exactes pour lutter contre les adventices existants.

Cependant, la lutte chimique présente des limites à causes des phénomènes de résistance observés (Boraud et al., 2010). Le coût des herbicides limite aussi son utilisation, ils peuvent avoir des conséquences sur la santé humaine (stérilité, cancer, etc.) et l'environnement (Kouadio et al., 2014). Face à ces insuffisances dans la gestion de l'enherbement, il est donc nécessaire de proposer aux agriculteurs des méthodes de luttes alternatives, combinant notamment le désherbage chimique et manuel, afin d'optimiser les rendements.

Le glyphosate dont l'utilisation comme molécule active a été mise au point lors de la conception du Roundup, durant les années 70 par John Franz, chercheur de la Compagnie Monsanto, est un désherbant total, c'est- àdire un herbicide non sélectif (Mazzella et al., 2009). Cependant, les informations obtenues de la littérature indiquent qu'il inhiberait la biosynthèse des composés phénoliques dont les flavonoïdes qui sont responsables de la bio protection des plantes (Kouassi Brou et al., 2012). De plus en plus d'espèces, développent l'accoutumance au glyphosate annihilant en partie les effets du Roundup. Le glyphosate appartient à la famille de Glycine (Tissut et al., 2006), il permet une destruction efficace des adventices. En forêt, le traitement avec le glyphosate aide au démarrage des semis et des jeunes plants. Cela évite la concurrence avec d'autres espèces végétales pendant les premières années de croissance des arbustes. Le Starane 200, composé actif: 29,6 \% Fluroxypyr-Meptyl, est un herbicide sélectif de post-levée à action systémique foliaire contre les mauvaises herbes annuelles, sous forme d'émulsion concentrée (EC) (Shah et al., 2006).

Ces deux produits actifs ont été utilisés comme herbicide, dans le cadre de notre étude dont l'objectif est d'évaluer leur effet sur les espèces les plus fréquentes dans la plantation d'Olam Rubber à Bitam.

\section{MATERIEL ET METHODES Zone d'étude}

Le site Batouri est situé à $34 \mathrm{~km} \mathrm{du}$ sud-est de la ville de Bitam, entre le département du Ntem dont le chef-lieu est Bitam et le département du Haut Ntem qui a pour chef-lieu Minvoul dans le Nord du Gabon (en Afrique Centrale). Les coordonnées géographiques du site sont: longitude Est $11^{\circ} 73$, latitude Nord $2^{\circ} 12$, (Olam, 2013). Le climat du Woleu-Ntem en général et celui de Bitam en particulier est de type équatorial marqué par deux saisons de pluies et deux saisons sèches: une grande saison sèche de juin à septembre et une moins prononcée de décembre à février. La petite saison de pluie va de mars à mai et la grande 
saison de pluie va de mi-septembre à minovembre. Le département du Ntem reçoit en moyenne entre $2100 \mathrm{~mm}$ et $1600 \mathrm{~mm}$ de pluie par an (1770 mm à Bitam) et la température moyenne est de $22{ }^{\circ} \mathrm{C}$. La classification de Koppen-Geiger est de type Am. En moyenne, la température à Bitam est $24,1{ }^{\circ} \mathrm{C}$ (Olam, 2013). La forêt dense humide sempervirente couvre la majeure partie de la surface provinciale. Cependant dans les zones habitées le long des axes de communication, on note la présence de plantations, jachères, brousses et forêts secondaires. Les sols du site de Batouri sont formés sur des roches métamorphiques acides. Il est ferralitique et fortement désaturé avec une texture argileuse et un horizon humifère peu épais. Il présente de bonnes qualités physiques et une capacité de rétention en eau qui conviennent à la culture de Hevea brasiliensis (Ondo et al., 2018).

\section{Matériel végétal}

Le matériel végétal de notre expérimentation est constitué des adventices les plus fréquentes identifiées et quantifiées sur la culture de l'hévéa de la zone d'étude.

\section{Matériel chimique}

Le matériel chimique utilisé pour notre étude est essentiellement composé de deux herbicides, le Supremo et le Starane qui sont les produits proposés par l'entreprise OlamRubber suite à leur récurrence lors des premiers essais (cas du Supremo) et à leur emploi quasi nul (cas du Starane).

- Le Supremo 41.0, composé actif: $41 \%$ glyphosate

Le glyphosate ( $\mathrm{N}$-(phosphonométhyl) glycine, $\mathrm{C}_{3} \mathrm{H}_{8} \mathrm{NO}_{5} \mathrm{P}$ ) est un désherbant total foliaire systémique. Il appartient à la classe III des herbicides. Il agit en bloquant l'enzyme enoylpyruvylshikimate 3-phosphate synthase (EPSPS).

- Le Starane 200 g/l, composé actif: 29,6\% Fluroxypyr-Meptyl

C'est un herbicide sélectif (antigraminée) de post-levée à action systémique foliaire contre les mauvaises herbes annuelles, sous forme d'émulsion concentrée (EC). Le Fluroxypyr $\left(\mathrm{C}_{7} \mathrm{H}_{5} \mathrm{Cl}_{2} \mathrm{FN}_{2} \mathrm{O}_{3}\right)$ appartient à la classe III des herbicides. Il est absorbé par les feuilles puis transporté par la sève dans la plante.

\section{Méthodologie \\ Conduite de l'essai \\ Première étape: relevés floristiques}

Un inventaire des adventices a été réalisé dans les parcelles d'hévéa les plus enherbées selon l'échantillonnage de la rame métrique. Une interligne enherbée constitue une unité d'échantillonnage. L'étude floristique réalisée dans le site sur 104 relevés de $1664 \mathrm{~m}^{2}$ a permis de recenser le nombre d'espèces présentes sur le site et de calculer la fréquence relative de chaque espèce identifiée.

\section{Deuxième étape : traitement herbicide}

Elle désigne le traitement proprement dit. Les observations ont été réalisées en parcelles expérimentales constituées des interlignes de l'hévéa. Sur les interlignes, 15 placettes de $60 \mathrm{~m}^{2}$ chacune ont toutes reçu des traitements herbicides (glyphosate, fluroxypyr ou les 2 combinés).

Les quantités de produits chimiques utilisés pour les différents traitements sont consignées dans le Tableau 2. Le traitement T0 étant le témoin, il a consisté à effectuer un désherbage manuel entre les lignes sur $60 \mathrm{~m}^{2}$. Chaque concentration de glyphosate ou de fluroxypyr a été complétée avec 20 litres d'eau courante pour obtenir un volume dilué qui a servi pour le traitement de chaque placette de $60 \mathrm{~m}^{2}$ à l'aide d'un pulvérisateur à pression préalable constante de 16 litres. L'application des produits s'est réalisée en début de matinée.

\section{Troisième étape : observations et relevés}

C'est la période qui consiste à observer l'effet des traitements sur les espèces de mauvaises herbes les plus fréquentes du site. La collecte de données a été faite tous les 3 jours jusqu'à la fin de la rémanence du produit en fonction des différents traitements appliqués.

Préparation des traitements

Notre étude s'est donc basée sur 15 traitements qui correspondent soit aux mélanges des différentes doses de glyphosate et de fluroxypyr, soit l'application individuelle de chaque produit (Tableau 2). 


\section{Description du dispositif expérimental}

Le dispositif expérimental mis en place était composé de 3 blocs d'interlignes, répartis dans chacun des 3 sites, comportant 16 placettes chacun. Sur chaque bloc, 15 placettes ont été traitées chimiquement et la dernière a servi de témoin (traitement manuel). Les différents traitements ont été répartis de manière aléatoire sur les interlignes. Le dispositif comportait donc au total 16 traitements $\mathrm{x} 3$ répétitions ce qui donne 48 unités expérimentales (Figure 1). Le choix d'individus était fonction du niveau d'enherbement. Dans chaque placette, 5 individus des espèces les plus fréquentes ont été marquées comme unité d'observation.

\section{Calcul de la fréquence}

La fréquence est le nombre de fois qu'une espèce a été rencontrée dans un échantillonnage comprenant $\mathrm{N}$ relevés. Elle a été calculée par la formule proposée par Daget et Poissonet (1969). Cette valeur au plan statistique est considérée comme une valeur absolue. On parle de fréquence relative lorsqu'on obtient un rapport exprimé en pourcentage entre le nombre de présences d'une espèce et le nombre total de points observés sur les $\mathrm{N}$ relevés. La fréquence peut concerner la plante entière ou une partie vivante de celle-ci. Dans ce dernier cas, la plante peut avoir sa souche dans la placette concernée et le reste en dehors de cette surface. Par ailleurs, le pied de la souche peut être à l'extérieur de cette surface et c'est le fragment qui, dans ce cas, est à l'intérieur de la surface. Elle constitue une «mesure » du recouvrement de l'espèce (Boraud, 2014). Les autres espèces ayant des fréquences inférieures à 5\% ont été écartées pour la suite de notre étude. Seuls les adventices présentant un pourcentage supérieur ou égal à 5\% ont été retenus pour l'étude de l'effet des traitements sur les adventices, hormis Ipomoea grandiflora qui a été choisie comme herbe de couverture à cause de sa propriété d'adventices rampantes qui couvre le sol au même titre que le Pueraria phaseolides, qui est utilisé comme couverture fertilisante sur le site.

\section{Les observations et expression des résultats}

Les observations ont été faites sur l'effet des deux produits chimiques combinés ou appliqués seuls pendant quatre mois (de juillet à octobre) sur le temps de fanaison, de jaunissement, de sénescence et de rémanence (fréquence d'apparition des espèces). Les observations sur l'effet des deux herbicides ont été faites sur une fiche de collecte de données et concernent les paramètres suivants: la fréquence de présence des espèces; le temps d'exécution des désherbages et le temps de fanaison des adventices: la fanaison des adventices s'explique par le flétrissement des adventices suite à l'apport des différents traitements chimiques. Elle a été observée sur une période d'une semaine. Le temps de jaunissement des adventices: le jaunissement des adventices s'est observé sur une période de 2 semaines. L'observation montre un virement progressif de la couleur des adventices. Le temps de sénescence des adventices: la sénescence correspond au temps mis pour observer le vieillissement et la mort complète des adventices après traitements. Elle a été observée sur une période d'un (01) mois. La rémanence des produits: la notion de rémanence renvoie à la persistance d'action d'un produit. Il est toujours nécessaire de s'assurer de l'absence d'arrière-effet d'un produit sur la culture suivante (Schrack et al., 2009).

Dans notre étude, la rémanence a été observée après la sénescence des adventices sur les différentes unités expérimentales qui ont reçu les traitements. Pour cela, il convient de montrer la durée d'efficacité des produits dans le sol en fonction des traitements, des espèces et des sites. Les résultats obtenus ont 
été comparés avec le traitement témoin (T0), qui est le désherbage manuel ou rond manuel.

\section{Analyse statistique des données}

L'analyse de la variance (ANOVA) a été utilisée pour comparer les moyennes des différents paramètres étudiés. L'ANOVA compare la variance intragroupe à la variance intergroupe. Il s'agit d'une analyse paramétrique, c'est- à- dire que l'on considère que la variable mesurée a une distribution normale. Le but de l'analyse est d'établir si les moyennes des valeurs mesurées dans différents groupes, sont significativement différentes. Elle repose sur trois principes: l'indépendance des observations, la normalité de la distribution, et l'homogénéité des variances. Le niveau de significativité choisi pour ces analyses, est de 5\% $(P=0,05)$. Chaque fois que la probabilité calculée était significative, le test de Newman-Keuls est effectué pour comparer deux à deux les moyennes et apprécier les différences significatives qui existent entre celles-ci. Le logiciel XLSTAT 2007.6 a été utilisé pour la réalisation de ces tests statistiques.

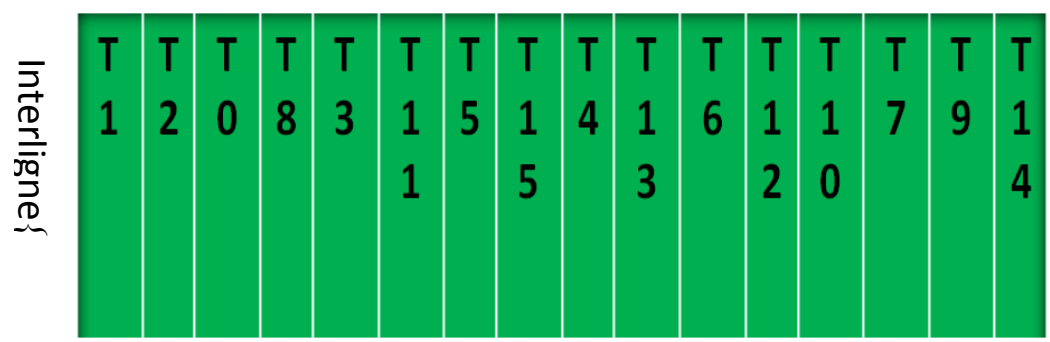

Bloc I : Site A1

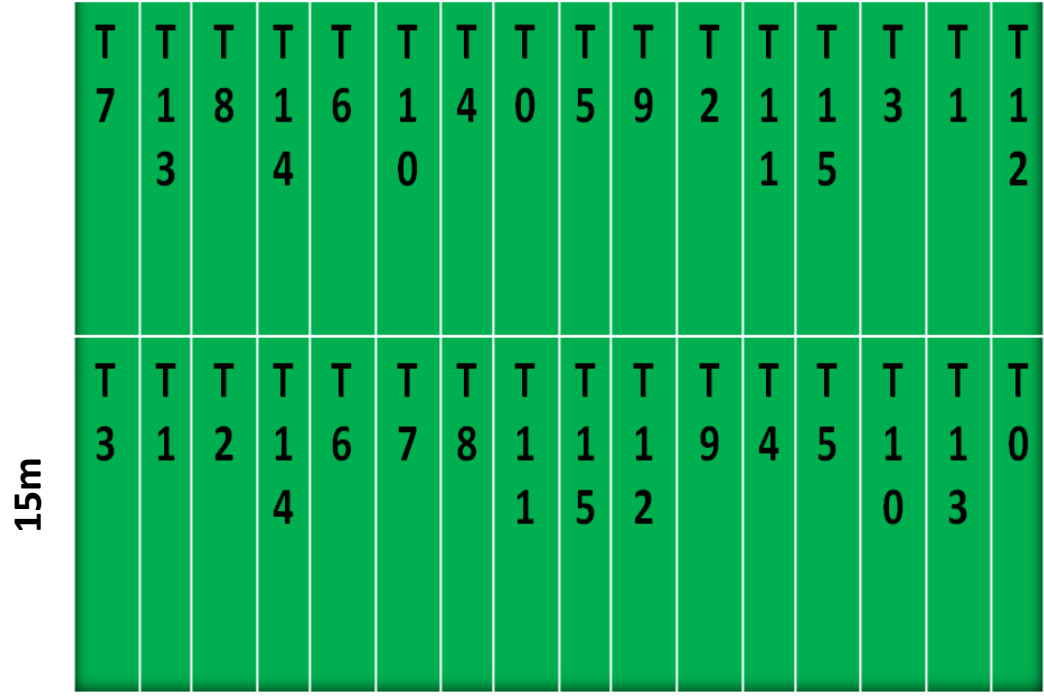

Bloc II : Site A8

Bloc III : Site A18

Figure 1 : Dispositif expérimental. 


\section{RESULTATS}

\section{Diversité floristique}

L'analyse floristique a permis d'identifier 42 espèces réparties entre 33 genres et 20 familles sur les parcelles les plus enherbées du site avec des fréquences variables. Les plus fréquemment rencontrées sont indiquées au Tableau 1.

\section{Temps d'exécution du désherbage chimique et manuel}

Les temps d'exécution du désherbage chimique et du désherbage manuel ont été déterminés sur chaque placette (Figure 2). Les résultats montrent que le temps moyen pour exécuter le désherbage chimique est de 21,63 minutes. Ce temps est inférieur à celui nécessaire pour le désherbage manuel $(36,57$ minutes). Le temps d'exécution d'un désherbage varie d'un bloc à l'autre en fonction de la végétation présente.

\section{Effet des traitements sur les paramètres étudiés}

Les résultats de l'effet des traitements (tous traitements confondus) sur les différents paramètres étudiés sont présentés dans le Tableau 1. L'analyse statistique de l'effet des traitements sur les temps de fanaison, de jaunissement, de sénescence et de rémanence a indiqué des différences hautement significatives $(\mathrm{P}<0,0001)$ au seuil de $5 \%$.

Les temps de fanaison sont équivalents et les plus courts pour les espèces $C$. bustamanta, $C$. odorata, $M$. cecropioides et $L$. citrata. Au contraire, le temps de fanaison de Melastoma sp, est le plus long observé. Le jaunissement qui précède la sénescence, survient au bout de 5 à 9 jours suivant les espèces, 5 jours pour $L$. citrata et 9 jours pour Melastoma sp. Selon les résultats du Tableau 1, l'effet des traitements sur le temps moyen de sénescence a varié de 10 jours (L. citrata) à 16 jours (Melastoma sp.). L'effet des traitements sur la rémanence a varié de 74 jours à 99 jours. Les résultats obtenus montrent que sur les huit espèces étudiées, seules quatre ont pu réapparaître. Cette rémanence est significativement différente pour ces quatre espèces $E$. valerianifolia, $C$. bustamanta, E. sonchifolia et $M$. cecropioides avec les valeurs respectives de 99, 85, 79 et 74 jours.

\section{Effet des doses sur les paramètres étudiés}

Les résultats de l'effet des doses sur le temps (en jours) de fanaison, de jaunissement, de senescence et de rémanence sont présentés dans le Tableau 2. L'analyse statistique de l'effet des doses sur le temps de fanaison, de jaunissement, de sénescence et de rémanence a révélé des différences hautement significatives $(\mathrm{P}<0,0001)$ au seuil de $5 \%$.

L'effet de la dose sur le temps moyen de fanaison a varié de 3,1 jours pour le traitement T12 à 5,2 jours pour le traitement T1. Les temps de fanaison les plus courts sont observés lors des traitements (T4 à T12), c'est-à-dire en présence de glyphosate associé à du fluroxypyr. Selon le Tableau 1, l'effet des doses sur le temps moyen de jaunissement a varié de 6,75 jours $(\mathrm{T} 10)$ à 9,8 jours pour les traitements $\mathrm{T} 13$ et T14. Les temps de jaunissement les plus courts sont observés lors des traitements (T4 à T12), c'est-à-dire en présence de glyphosate associé à du fluroxypyr. La présence d'un seul herbicide rallonge le temps de jaunissement.

L'effet des doses sur le temps moyen de sénescence a varié significativement de 12,2 jours (T6) à 17,8 jours (T13). Comme pour la fanaison et le jaunissement, les temps de sénescence les plus courts sont observés dans des traitements (T4 à T12), c'est-à-dire en présence de glyphosate associé à du fluroxypyr. Les temps de sénescence les plus longs sont généralement observés en présence de fluroxypyr seul (T13 à T15). L'effet des doses sur la rémanence a varié de 39,3 jours (T0) à 92,0 jours (T12). La présence d'au moins un des herbicides permet de doubler le temps de rémanence.

\section{Effet des sites sur les paramètres étudiés}

Les résultats de l'effet des sites sur les différents paramètres étudiés sont présentés dans le Tableau 3. L'analyse statistique des données de l'effet des différents sites sur le temps de fanaison et de sénescence indique des différences hautement significatives 
$(\mathrm{P}<0,0001)$ au seuil de 5\%. Par contre, l'analyse statistique de l'effet des sites sur le temps de jaunissement et de rémanence ne montre aucune différence significative, respectivement $(\mathrm{P}=0,059)$ et $(\mathrm{P}<0,189)$ au seuil de $5 \%$.

Le temps moyen de fanaison au niveau des différents sites a varié de 3,6 jours pour le site A18 à 4,1 jours pour le site A1. L'effet des sites sur le temps moyen de sénescence a varié de 13,9 jours (A8) à 14,95 jours (A1). Les temps moyens de sénescence des trois sites sont significativement différents entre eux.

\section{Interaction Espèces*Traitements}

L'analyse statistique des données sur les interactions Espèces*Traitements a révélé des différences hautement significatives $(\mathrm{P}<$ $0,0001)$ au seuil de $5 \%$ pour les temps de fanaison, de jaunissement et de sénescence.

En ce qui concerne l'interaction Espèces*Traitements sur le temps de fanaison (Figure 3), nous distinguons deux groupes : le premier groupe est composé des espèces Melastoma sp, E. valerianifolia, E. sonchifolia et $D$. erecta qui sont les moins sensibles aux différents traitements avec des temps moyens de fanaison atteignant parfois 6,3 jours pour l'espèce Melastoma sp au traitement T1. Dans ce groupe, l'effet dose est observable par une diminution du temps de fanaison de l'espèce la moins sensible du groupe (Melastoma $s p$ ) aux traitements $\mathrm{T} 6$ et $\mathrm{T} 12$. Le second groupe est composé des espèces $L$. citrata, $M$. cecropioides, $C$. odorata et $C$. bustamanta qui se sont montrées très sensibles à tous les traitements. Parmi les plus sensibles, l'espèce L. citrata enregistre les temps moyens de fanaison les plus courts (inférieurs à 4 jours) pour les traitements allant de T4 à T15.

En considérant l'interaction Espèces*Traitements sur le temps de jaunissement (Figure 4), nous distinguons également deux groupes: le premier groupe est composé des espèces Melastoma sp, E. valerianifolia, $E$. sonchifolia, D. erecta, $C$. bustamanta, $M$. cecropioides et $C$. odorata qui sont les moins sensibles aux différents traitements avec des temps moyens de jaunissement atteignant parfois 12 jours pour l'espèce $C$. bustamanta aux traitements T13 et T15. Le second groupe est composé uniquement de l'espèce $L$. citrata. Cette dernière s'est montrée très sensible aux traitements avec des temps moyens de jaunissement très courts (inférieurs à 8 jours).

L'interaction Espèces*Traitements sur le temps de sénescence permet de distinguer les deux mêmes groupes (Figure 5): le premier groupe composé des espèces les moins sensibles aux différents traitements avec des temps moyens de sénescence atteignant 22,3 jours pour l'espèce $M$. cecropioides au traitement T1. L'effet dose est observé avec une diminution du temps de sénescence de l'espèce la moins sensible du groupe (M. cecropioides) aux traitements T10 et T11. D'autre part, l'espèce $L$. citrata qui s'est montrée très sensible aux traitements avec des temps moyens de sénescence très courts atteignant 9 jours aux traitements T10 et T11. De façon générale, les traitements les plus adaptés sont généralement les associations des deux herbicides qui réduisent les temps de fanaison, de jaunissement et de sénescence pour toutes les espèces (notamment $\mathrm{T} 10$ et T11).

\section{Interaction Espèces*Sites}

L'interaction

possible

Espèces*Sites sur les paramètres étudiés est présentée sur la Figure 6. L'analyse statistique des données sur l'interaction Espèces*Sites sur le temps de fanaison a montré des différences hautement significatives $(\mathrm{P}<$ 0,0001 ) au seuil de $5 \%$. Trois groupes sont déterminés : le premier groupe est composé des espèces E. valerianifolia, E. sonchifolia, $D$. erecta, $C$. bustamanta et $C$. odorata qui présentent un temps court de fanaison sur le site A18. Le second groupe est constitué des espèces $M$. cecropioides et Melastoma $s p$ qui sont plus sensibles à la fanaison sur le site A8. Enfin le groupe composé de L. citrata et Melastoma sp qui enregistrent un temps court de fanaison sur le site A1.

L'analyse statistique des données sur l'interaction Espèces*Sites sur le temps moyen de jaunissement n'a révélé aucune 
différence significative $(\mathrm{P}=0,109)$ au seuil de $5 \%$. Par contre, cette analyse sur l'interaction Espèces*Sites sur le temps de sénescence a montré des différences significatives $(\mathrm{P}=0,004)$ au seuil de 5\%. Deux groupes sont déterminés: le premier composé de l'espèce $L$. citrata qui présente un temps moyen de sénescence plus court ( 9,5 jours) sur le site

\section{Interaction Traitements*Sites}

L'interaction possible Traitements *Sites sur les paramètres étudiés est schématisée sur les Figures 7 à 9. L'analyse statistique des données sur l'interaction Traitements*Sites sur les temps de fanaison, de jaunissement et de sénescence a indiqué des différences significatives (respectivement $\mathrm{P}=0,019, \mathrm{P}=0,014$ et $\mathrm{P}=0,047$ ) au seuil de 5\%.

L'interaction Traitements*Sites sur le temps de fanaison (Figure 7), montre que les sites A8 et A18 enregistrent les temps moyens de fanaison les plus courts, particulièrement avec les traitements T5 à T12. Le traitement le plus adapté pour les trois sites est le traitement T12 avec 3 jours (A8), 3,12 jours (A18) et 3,25 jours (A1).
A18, suivie de l'espèce $E$. valerianifolia sur le site A8. Le second groupe est composé des espèces $D$. erecta, $C$. bustamanta, $E$. sonchifolia, M. cecropioides, C. odorata et Melastoma sp qui sont les moins sensibles. Dans ce groupe, l'effet site est marqué pour l'espèce $D$. erecta dont la sénescence est plus rapide sur le site A18.

L'interaction Traitements*Sites sur le temps de jaunissement (Figure 8), indique que les sites A1 et A8 enregistrent les temps moyens de jaunissement les plus courts spécialement avec le traitement T10.

En considérant l'interaction Traitements*Sites sur le temps de sénescence (Figure 9), les sites A8 et A18 enregistrent les temps moyens de sénescence les plus courts avec le traitement T6. Ce dernier est le plus adapté pour les trois sites avec 11,63 jours (A8), 12,50 jours (A18 et A1). L'effet dose est observable sur les trois sites par une diminution du temps de sénescence avec l'application seule du glyphosate (T1 à T3) et les combinaisons des deux herbicides (T4 à T12).

Tableau 1 : Fréquence des adventices recensés. Effet des traitements sur le temps (en jours) de fanaison, de jaunissement, de sénescence et de rémanence.

\begin{tabular}{|c|c|c|c|c|c|}
\hline Espèces & Fréquence & $\begin{array}{c}\text { Fanaison } \\
\text { (Jours) }\end{array}$ & $\begin{array}{c}\text { Jaunissement } \\
\text { (Jours) }\end{array}$ & $\begin{array}{l}\text { Sénescence } \\
\text { (Jours) }\end{array}$ & $\begin{array}{c}\text { Rémanence } \\
\text { (Jours) }\end{array}$ \\
\hline C. bustamanta & 5,02 & $3,67^{\mathrm{cd}}$ & $8,18^{\mathrm{c}}$ & $15,02^{\mathrm{b}}$ & $84.52^{\mathrm{b}}$ \\
\hline C. odorata & 5,34 & $3,51^{\mathrm{d}}$ & $8,60^{b}$ & $15,98^{a}$ & - \\
\hline D. erecta & 5,18 & $3,91^{\mathrm{bc}}$ & $8,56^{\mathrm{b}}$ & $15,29^{\mathrm{b}}$ & - \\
\hline E. sonchifolia & 6,31 & $4,20^{\mathrm{b}}$ & $8,73^{b}$ & $14,82^{b}$ & $78.96^{\mathrm{c}}$ \\
\hline $\begin{array}{c}E . \\
\text { valerianifolia }\end{array}$ & 7,44 & $4,02^{\mathrm{bc}}$ & $7,60^{\mathrm{d}}$ & $13,22^{c}$ & $99.16^{\mathrm{a}}$ \\
\hline L. citrata & 5,83 & $3,29^{d}$ & $5,00^{\mathrm{e}}$ & $10,13^{d}$ & - \\
\hline $\begin{array}{c}M . \\
\text { cecropioides }\end{array}$ & 7,77 & $3,42^{\mathrm{d}}$ & $7,64^{\mathrm{d}}$ & $14,84^{b}$ & $74.31^{\mathrm{d}}$ \\
\hline Melastoma sp. & 5,02 & $4,71^{\mathrm{a}}$ & $9,33^{a}$ & $16,40^{a}$ & - \\
\hline
\end{tabular}

*Les valeurs suivies de la même lettre dans une même colonne ne sont pas significativement différentes selon le test de Newman Keuls au seuil de 5\%. 


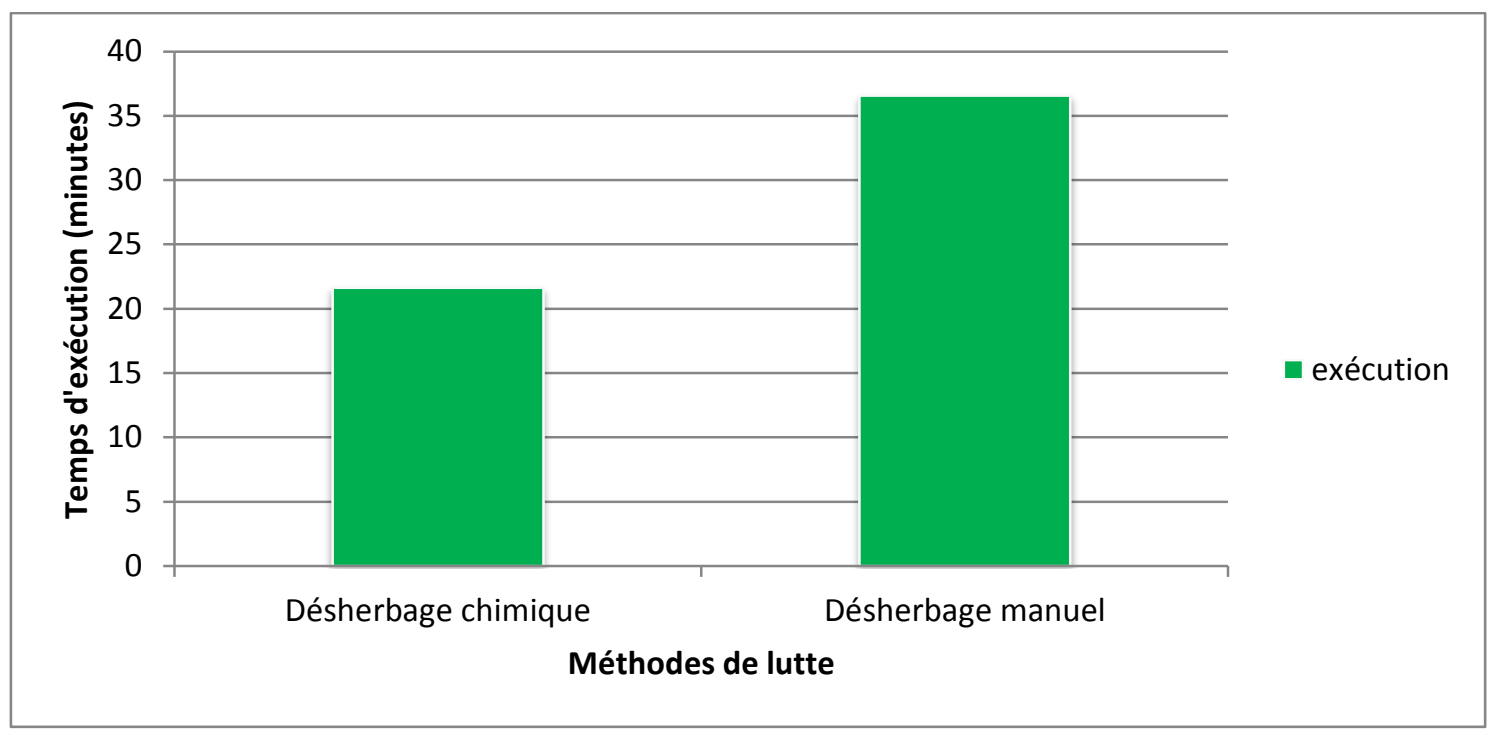

Figure 2 : Temps d'exécution des désherbages chimique et manuel (en minutes).

Tableau 2 : Traitements et quantités de glyphosate et fluroxypyr utilisés sur une placette de $60 \mathrm{~m}^{2}$. Effet des doses sur le temps (en jours) de fanaison, de jaunissement, de sénescence et de rémanence.

\begin{tabular}{|c|c|c|c|c|c|c|}
\hline \multirow[t]{2}{*}{ Traitements } & \multicolumn{2}{|c|}{ Doses (ml) } & \multirow{2}{*}{$\begin{array}{c}\text { Fanaison } \\
\text { (Jours) }\end{array}$} & \multirow{2}{*}{$\begin{array}{c}\text { Jaunissement } \\
\text { (Jours) }\end{array}$} & \multirow{2}{*}{$\begin{array}{c}\text { Sénescence } \\
\text { (Jours) }\end{array}$} & \multirow{2}{*}{$\begin{array}{c}\text { Rémanence } \\
\text { (Jours) }\end{array}$} \\
\hline & Glyphosate & Fluroxypyr & & & & \\
\hline T0 & - & - & - & - & - & $39,33^{\mathrm{d}}$ \\
\hline $\mathrm{T} 1$ & 50 & - & $5,21^{\mathrm{a}}$ & $9,21^{b}$ & $16,38^{b c}$ & $79,98^{a b c}$ \\
\hline $\mathrm{T} 2$ & 100 & - & $4,83^{a b}$ & $8,67^{c}$ & $15,92^{\mathrm{c}}$ & $84,00^{a b}$ \\
\hline T3 & 150 & - & $4,63^{b c}$ & $8,17^{\mathrm{d}}$ & $14,21^{\mathrm{d}}$ & $86,42^{a b}$ \\
\hline $\mathrm{T} 4$ & 50 & 25 & $3,46^{\mathrm{e}}$ & $7,17^{\text {ef }}$ & $13,71^{\mathrm{de}}$ & $84,75^{\mathrm{ab}}$ \\
\hline T5 & 50 & 50 & $3,29^{\mathrm{e}}$ & $7,54^{\mathrm{e}}$ & $14,04^{\mathrm{d}}$ & $82,65^{\mathrm{ab}}$ \\
\hline T6 & 50 & 75 & $3,33^{\mathrm{e}}$ & $7,38^{\text {ef }}$ & $12,21^{\mathrm{f}}$ & $91,54^{\mathrm{ab}}$ \\
\hline $\mathrm{T} 7$ & 100 & 25 & $3,46^{\mathrm{e}}$ & $7,17^{\text {ef }}$ & $13,75^{\mathrm{de}}$ & $79,09^{b c}$ \\
\hline $\mathrm{T} 8$ & 100 & 50 & $3,67^{\mathrm{de}}$ & $6,88^{\text {ef }}$ & $13,54^{\mathrm{de}}$ & $84,65^{a b}$ \\
\hline T9 & 100 & 75 & $3,33^{\mathrm{e}}$ & $6,96^{\text {ef }}$ & $13,38^{\text {de }}$ & $85,54^{a b}$ \\
\hline $\mathrm{T} 10$ & 150 & 25 & $3,29^{\mathrm{e}}$ & $6,75^{\mathrm{f}}$ & $12,79^{\text {ef }}$ & $78,87^{\mathrm{bc}}$ \\
\hline $\mathrm{T} 11$ & 150 & 50 & $3,21^{\mathrm{e}}$ & $7,21^{\text {ef }}$ & $12,92^{\text {ef }}$ & $84,54^{a b}$ \\
\hline $\mathrm{T} 12$ & 150 & 75 & $3,13^{\mathrm{e}}$ & $6,96^{\text {ef }}$ & $12,96^{\text {ef }}$ & $91,98^{\mathrm{a}}$ \\
\hline $\mathrm{T} 13$ & - & 25 & $4,54^{b c}$ & $9,83^{a}$ & $17,83^{\mathrm{a}}$ & $71,83^{\mathrm{c}}$ \\
\hline T14 & - & 50 & $4,08^{\mathrm{cd}}$ & $9,83^{\mathrm{a}}$ & $17,04^{b}$ & $87,09^{a b}$ \\
\hline T15 & - & 75 & $4,17^{\mathrm{cd}}$ & $9,63^{a b}$ & $16,29^{b c}$ & $90,58^{a b}$ \\
\hline
\end{tabular}

*Les valeurs suivies de la même lettre dans une même colonne ne sont pas significativement différentes selon le test de Newman Keuls au seuil de 5\%. 
Tableau 3 : Effet des sites sur le temps (en jours) de fanaison, de jaunissement, de sénescence et de rémanence.

\begin{tabular}{ccccc}
\hline Site & $\begin{array}{c}\text { Fanaison } \\
(\text { Jours })\end{array}$ & $\begin{array}{c}\text { Jaunissement } \\
\text { (Jours) }\end{array}$ & $\begin{array}{c}\text { Sénescence } \\
\text { (Jours) }\end{array}$ & $\begin{array}{c}\text { Rémanence } \\
\text { (Jours) }\end{array}$ \\
\hline A1 & $4,12^{\mathrm{a}}$ & $7,86^{\mathrm{a}}$ & $14,95^{\mathrm{a}}$ & $82,95^{\mathrm{a}}$ \\
\hline $\mathrm{A} 8$ & $3,78^{\mathrm{b}}$ & $7,91^{\mathrm{a}}$ & $13,93^{\mathrm{c}}$ & $83,91^{\mathrm{a}}$ \\
\hline A18 & $3,63^{\mathrm{b}}$ & $8,10^{\mathrm{a}}$ & $14,52^{\mathrm{b}}$ & $85,85^{\mathrm{a}}$ \\
\hline
\end{tabular}

*Les valeurs suivies de la même lettre dans une même colonne ne sont pas significativement différentes selon le test de Newman Keuls au seuil de 5\%.

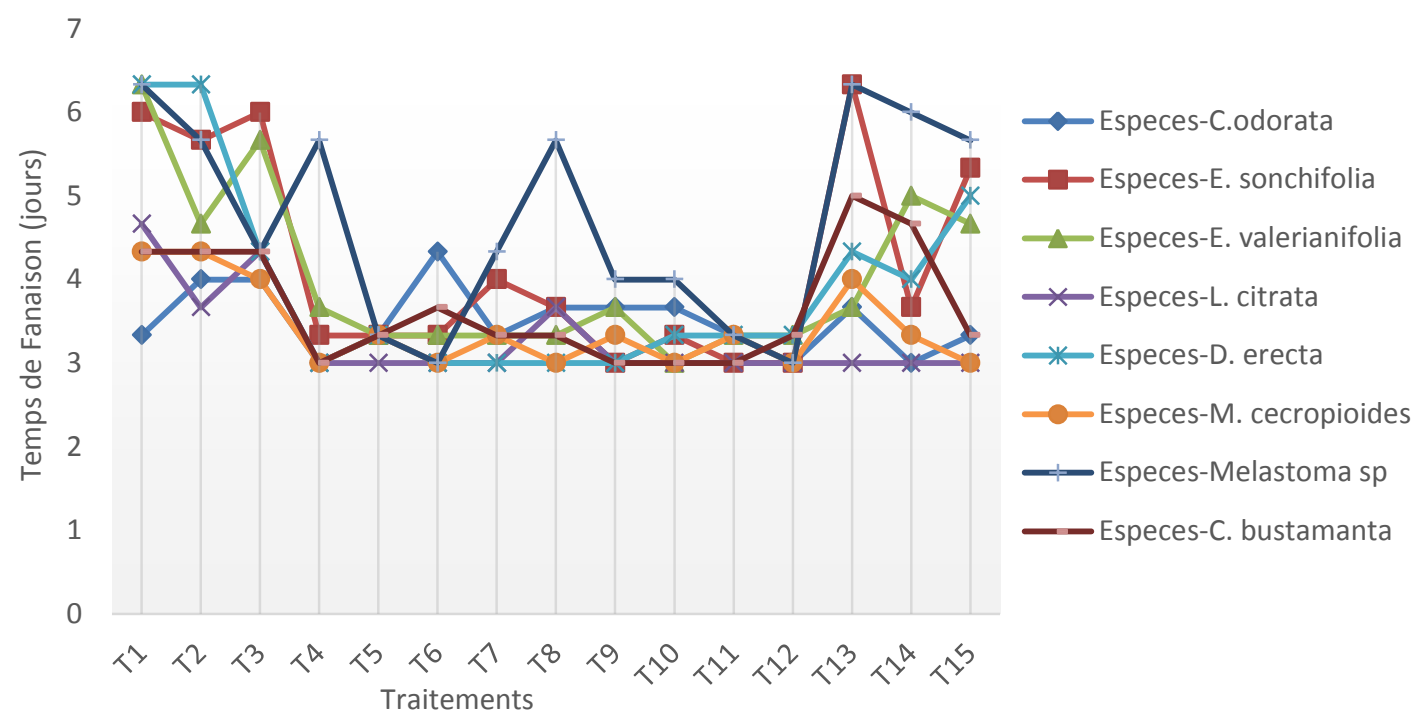

Figure 3 : Interaction Espèces*Traitements sur le temps (en jours) de fanaison.

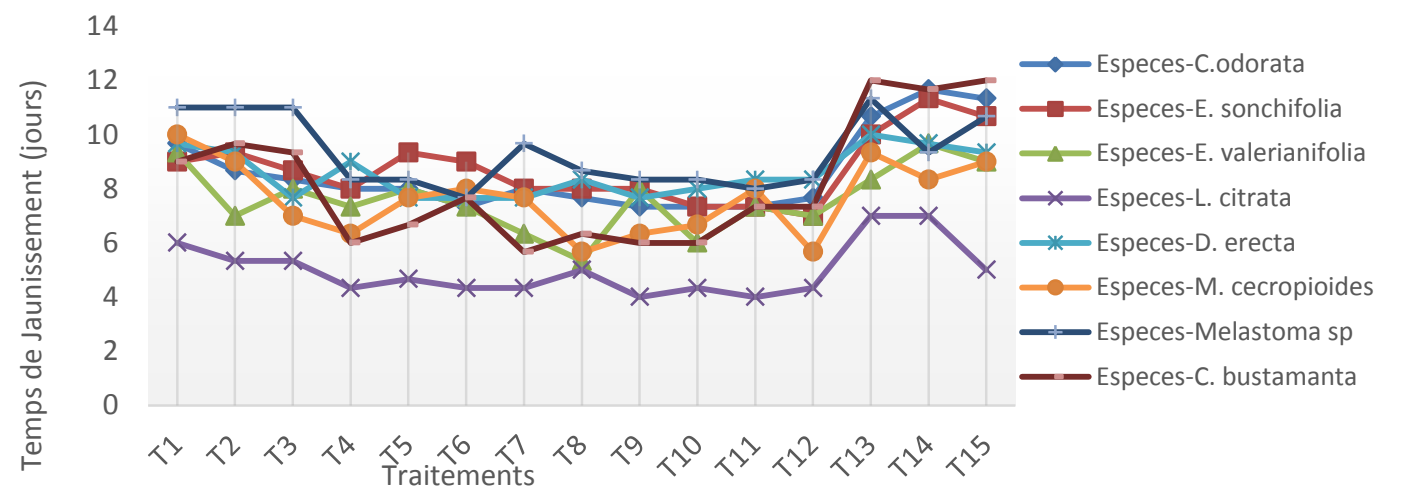

Figure 4 : Interaction Espèces*Traitements sur le temps (en jours) de jaunissement. 


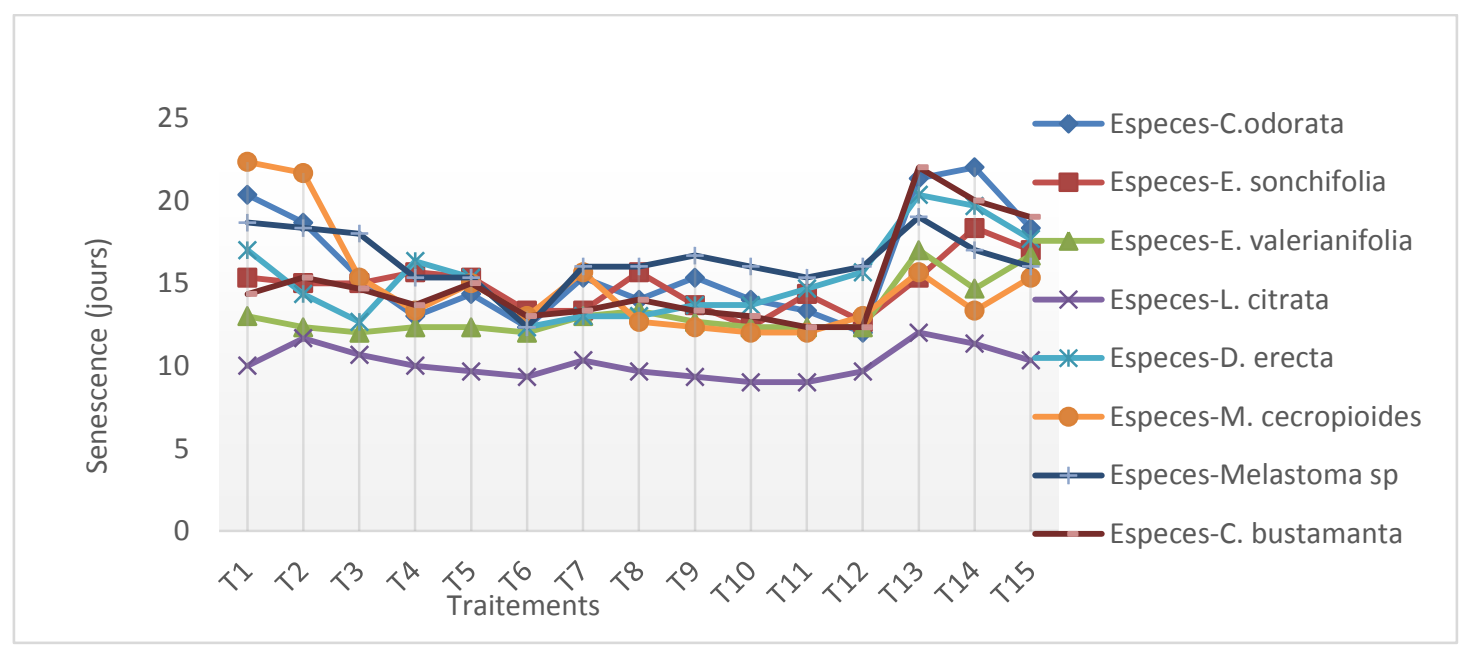

Figure 5 : Interaction Espèces*Traitements sur le temps (en jours) de sénescence.

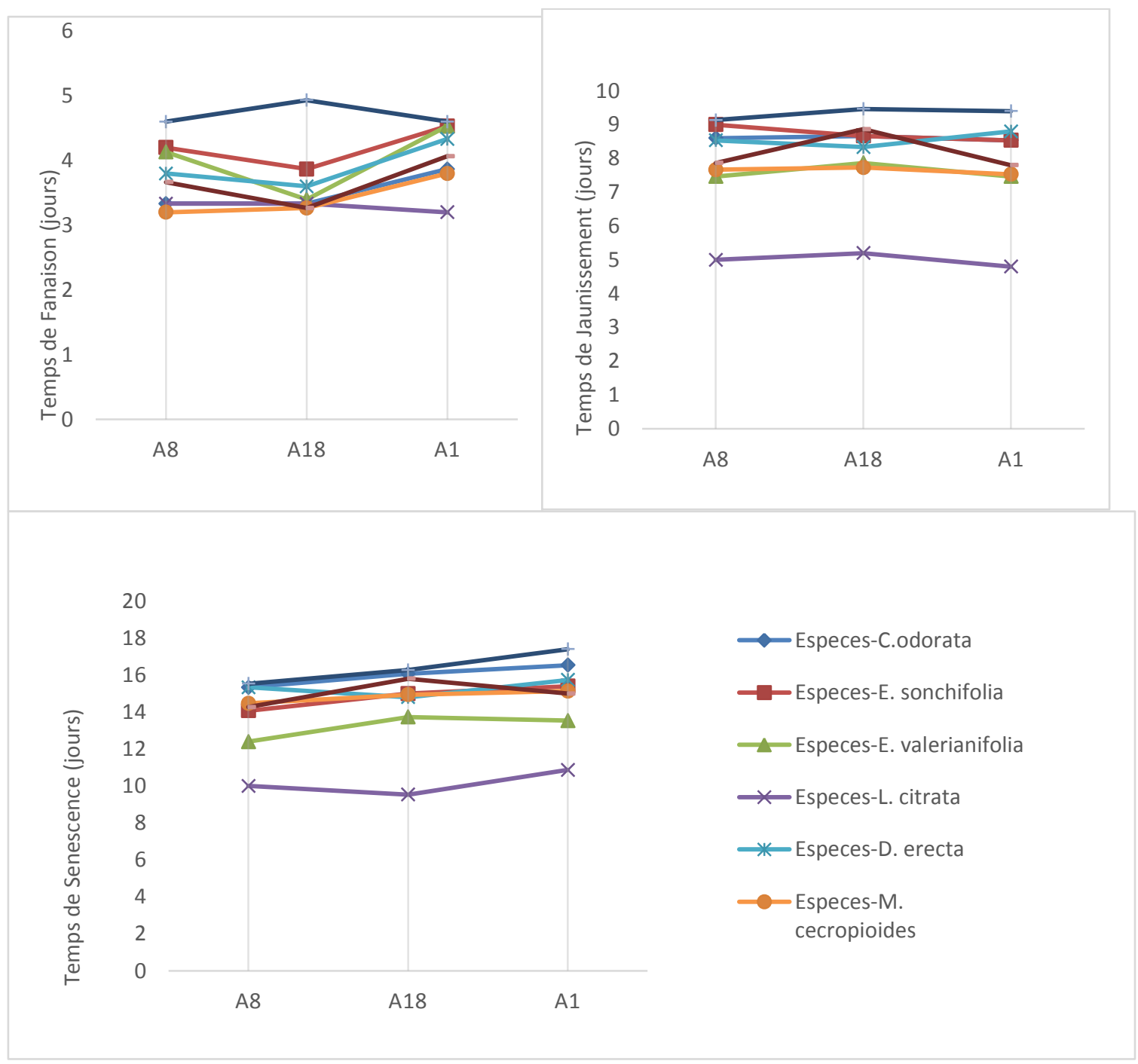

Figure 6 : Interaction Espèces*Sites sur le temps (en jours) de fanaison, de jaunissement et de sénescence. 


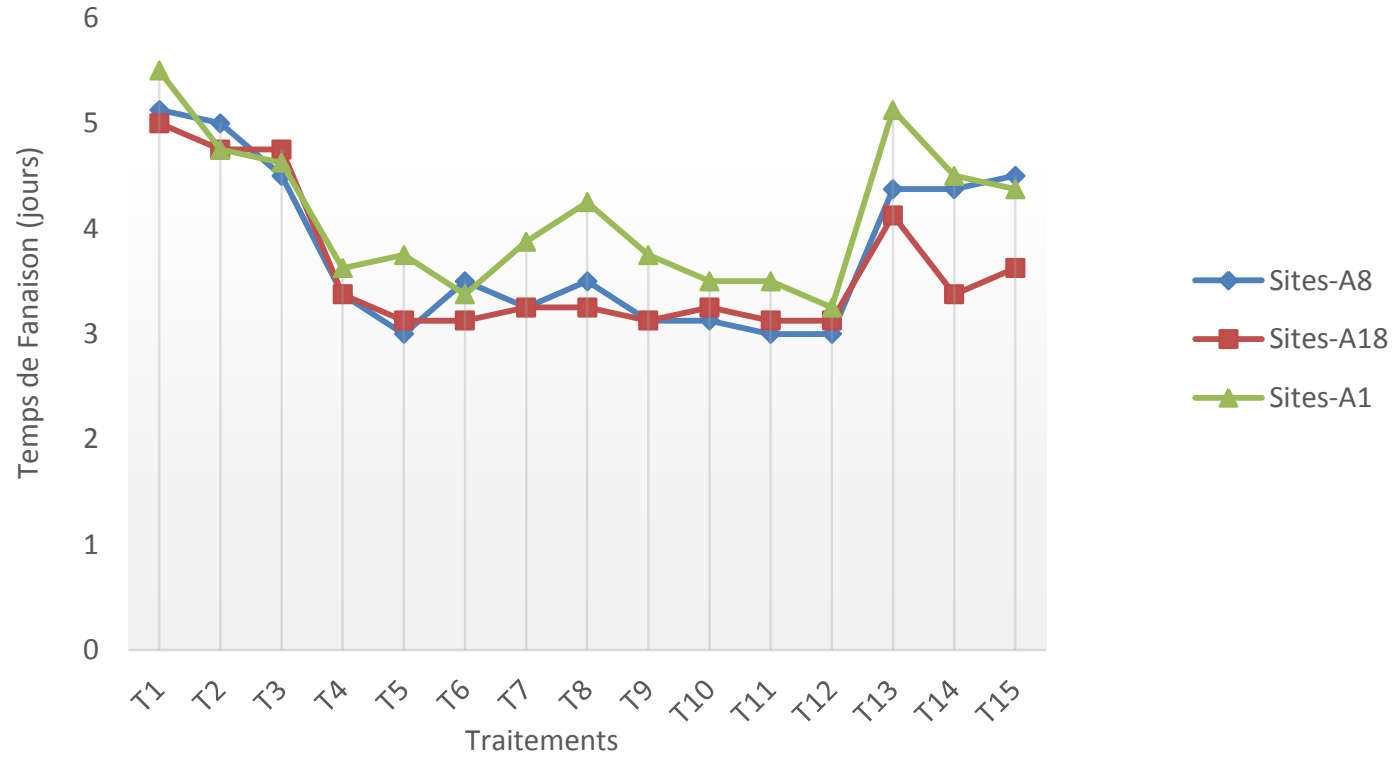

Figure 7 : Interaction Traitements*Sites sur le temps (en jours) de fanaison.

12

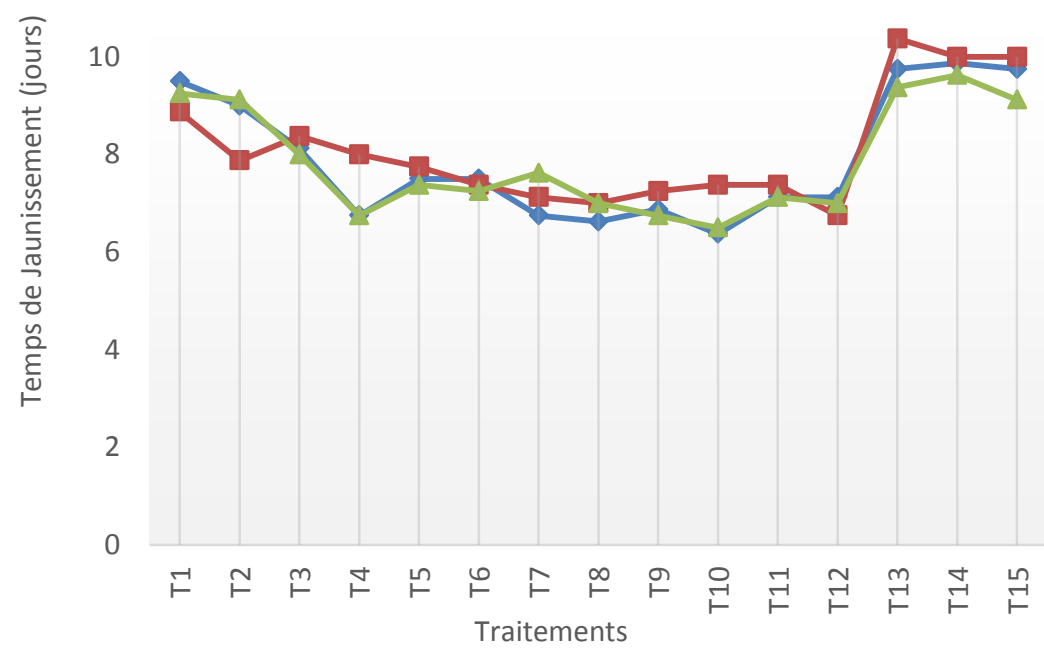

Figure 8 : Interaction Traitements*Sites sur le temps (en jours) de jaunissement. 


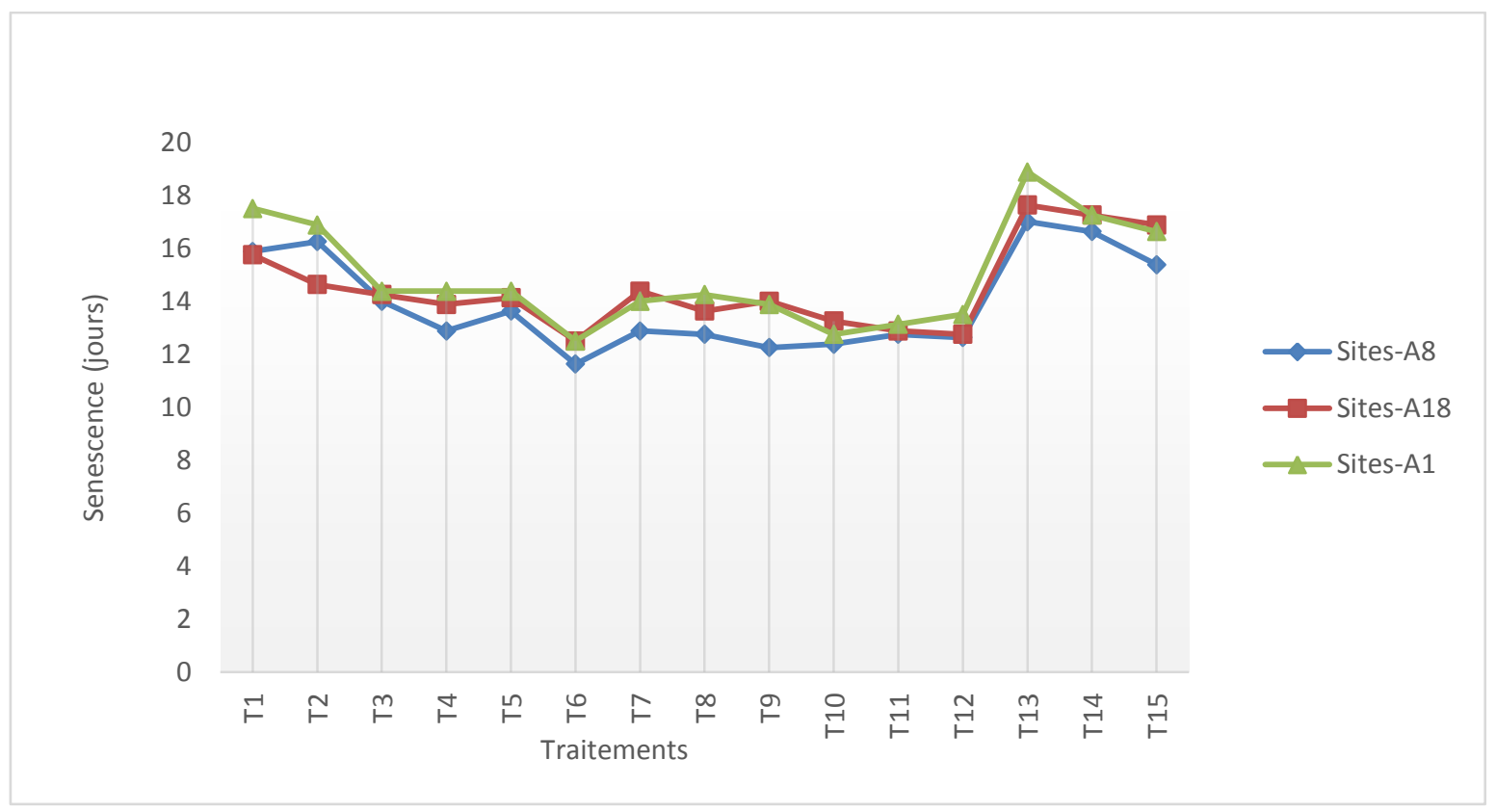

Figure 9 : Interaction Traitements*Sites sur le temps (en jours) de sénescence.

\section{DISCUSSION}

La lutte contre les mauvaises herbes est une étape clé pour une agriculture performante. L'utilisation de désherbants à base de glyphosate s'est généralisée dans le monde $\mathrm{du}$ fait des multiples avantages présentés par cette substance active pour lutter contre les adventices présentes dans une large gamme de rotations de cultures (Bertonnier et al., 2012 ; Pierre -Louis, 2013). L'usage systémique des herbicides dans les modes agricoles à OlamRubber semble donc aller dans ce sens, en se reposant sur l'utilisation systémique des herbicides.

À travers l'étude de l'effet des herbicides à base de glyphosate et fluroxypyr sur les espèces d'adventices les plus fréquentes dans la culture d'hévéa sur le site de Batouri, au Nord du Gabon, il ressort que le temps de réalisation des deux modes de désherbage (désherbage manuel et désherbage chimique) est lié à l'importance de la flore adventice et plus particulièrement de la densité et de la résistance des espèces à combattre. Dans tous les cas, le temps d'exécution du traitement chimique reste toujours inférieur à celui du désherbage manuel. Ce constat s'explique par le fait que le désherbage manuel est très laborieux vu la végétation présente sur les interlignes des hévéas. Ces observations rejoignent celles faites par Akintayo et al. (2008). Ces auteurs indiquent que le désherbage manuel sur les adventices du riz pluvial est difficile, pénible et long. Le désherbage chimique pour sa part ne nécessite pas beaucoup d'efforts physiques. Cette tendance est similaire aux observations de Bertonnier et al. (2012), qui affirment que le désherbage chimique est plus efficace et surtout beaucoup moins coûteux que le désherbage mécanique.

L'inventaire floristique sur la culture d'hévéa a permis d'identifier 42 espèces réparties entre 33 genres et 20 familles. Les espèces Chromolaena odorata, Cuphea bustamanta, Duranta erecta, Emilia sonchifolia, Erichtites valerianifolia, Lippia citrata, Melastoma $s p$ et Musanga cecropioides se sont révélées les plus fréquentes. Les 10 familles contenant le plus d'espèces considérées comme des mauvaises herbes majeures mondiales (Poaceae, Asteraceae, Cyperaceae, Polygonaceae, Amaranthaceae, Fabaceae, Convolvulaceae, Euphorbiaceae, Malvaceae, Solanaceae) figurent parmi les plus représentatives, respectivement dans les relevés de Tiébré et al. (2016) ; Bakayoko et al. (2016) ; Ndotam 
et al. (2017) ; Ahonon et al. (2018) ; Amegnaglo et al. (2018) sont présentes dans cette flore. Les différentes espèces étudiées n'ont pas les mêmes comportements vis à vis des herbicides.

En effet, pour les temps de fanaison, de jaunissement et de sénescence, l'espèce $L$. citrata est la plus sensible, présentant les temps les plus courts. Ces observations permettent de constater que la vitesse de sénescence est liée à celle du jaunissement étant donné que le jaunissement constitue une étape intermédiaire avant la sénescence des adventices.

Notre étude a également montré que les traitements favorables à l'éradication rapide des espèces sont $\mathrm{T} 12$, $\mathrm{T} 10$ et $\mathrm{T} 6$ qui provoquent respectivement les plus courts temps moyens de fanaison (3,13jours), de jaunissement $(6,75$ jours $)$ et de sénescence (12,21 jours). Ces résultats s'expliquent du fait que ces traitements sont combinés soit à forte dose de glyphosate ou de fluroxypyr ; contrairement à l'application seule des deux herbicides.

Le glyphosate seul est peu efficace, car il n'adhère pas aux feuilles et les pénètre difficilement. Pour accroître sa solubilité, il est donc habituellement préparé sous forme de sel d'isopropylamine ou bien des additifs ou des surfactants lui sont ajoutés pour le fixer sur les plantes (Le Mer et al. 2009). De même Komba (2013); Ekhator et al. (2018), ont montré que les meilleurs résultats sont obtenus avec de fortes doses de Roundup (Glyphosate) en association avec Ally (Metsulfuron methyl) sur le désherbage chimique du palmier à huile. Par contre, Boraud et al. (2010) affirment que le glyphosate seul, quelle que soit la dose a une efficacité de 80 à $90 \%$ sur les espèces caractéristiques du milieu en éliminant les adventices moins résistantes au profit des plus robustes. Ofosu-Bodu et al. (2014) de leur côté, ont montré que l'utilisation de Glisat (glyphosate) à la dose de 1,4 1/ha seul est plus efficace qu'en mélange et permet une réduction de $80 \%$ du poids sec des recrûs de C. odorata. Selon Ayichedehou (2000), C. odorata une espèce très envahissante qui colonise tous les milieux. Elle est perçue actuellement comme l'une des adventices les plus préoccupantes pour l'agriculture et l'élevage. Touré et al. (2008) ont aussi rapporté que $C$. odorata est l'espèce la plus préoccupante de la zone. Elle a la capacité, non seulement de se régénérer à partir de sa racine, mais également présente une très importante production de semences.

$\mathrm{La}$ rémanence des herbicides est appréhendée par le terme de demi-vie (DT50), plus la DT50 est faible, plus la rémanence du produit est faible. Plus le produit se dégrade vite, plus sa durée d'action est courte et plus rapidement il disparaîtra de l'environnement (Mamy, 2001). Les traitements qui se sont révélés efficaces dans notre expérience ont une vie résiduelle dans le sol de longueur variable. Ces résultats sont en accord avec les travaux de Hurrell et al. (2008) qui ont montré que la demi-vie du fluroxypyr et de l'amitrole dans le sol est relativement courte (de 3 à 4 semaines), celle du metsulfuron-methyl et de triclopyr est d'environ 5 à 6 semaines, tandis que picloram a la plus longue demi-vie (environ 14 semaines).

Les traitements à plus longue rémanence sont ceux où l'on a appliqué soit, le fluroxypyr seul à forte dose (T15) avec 90,6 jours de rémanence, soit le mélange à faible ou forte dose du glyphosate avec la forte dose $\mathrm{du}$ fluroxypyr (T6,T12) avec 91,54 et 92 jours de rémanence, respectivement. Ces résultats sont en accord avec ceux de Laitinen et al. (2006) et de Mamy et al. (2008). En effet, ces auteurs ont montrés que le glyphosate, et en particulier l'AMPA, peuvent persister dans les sols plusieurs semaines ou mois après application. La mobilité verticale dans le sol du glyphosate est à priori limitée en raison de sa forte capacité à être retenu par les constituants des sols. Cette mobilité réduite et une relative faible persistance du glyphosate expliquent qu'il soit rarement observé en profondeur, contrairement à l'AMPA qui peut être retrouvé dans les eaux souterraines (Mamy et al., 2008).

Du point de vue de la rétention et de la persistance des herbicides dans les sols, le glyphosate, est un herbicide fortement retenu 
dans les sols, plus de 60\% des quantités apportées se fixent sur les particules du sol (Mamy et al., 2011). Par rapport à des herbicides dont la rétention est limitée, le glyphosate présente donc l'avantage de sa très faible mobilité potentielle et devrait permettre de réduire les risques de contamination des eaux souterraines (Mamy et Borriuso, 2005). Cependant, dans les sols à $\mathrm{pH}$ acide, le glyphosate est plus persistant que le métazachlore et la sulcotrione (Mamy et al., 2011). La formation d'un métabolite majeur a été observée dans les cas du glyphosate (AMPA), du métazachlore et de la sulcotrione (Mamy et al., 2011). La persistance de ces métabolites est bien supérieure à celles des herbicides (quelques mois à quelques années): en conséquence ils présentent des risquent potentiels pour l'environnement plus importants que les herbicides (Mamy et al., 2005). En effet, plus la persistance d'une molécule dans le sol est élevée, plus les risques d'accumulation sont élevés et plus elle est susceptible d'être transférée vers l'eau (à l'état dissous ou particulaire) et l'air (Calvet et al., 2005).

L'effet des espèces sur la rémanence des produits a montré que sur les huit espèces de notre étude, seules quatre ont pu réapparaitre. Cela se justifie par le fait que les deux herbicides utilisés sont essentiellement systémiques et que le fluroxypyr perturbe le métabolisme protéique. Ils pénètrent et détruisent les adventices jusqu'au système racinaire. Le glyphosate bloque la biosynthèse des acides aminés aromatiques. Plus précisément, il inhibe un des enzymes impliqués dans la biosynthèse de ces acides aminés : il s'agit de la 5énolpyruvylshikimate-3-phosphate synthétase (EPSPS), une enzyme située majoritairement dans les chloroplastes et essentielle à la synthèse des acides aminés aromatiques (phénylalanine, tyrosine, tryptophane). Cette voie métabolique n'existe pas chez les insectes, les poissons, les oiseaux et les mammifères y compris l'homme. Le mode d'action du glyphosate n'est donc pas applicable à ces espèces (Pierre-Louis, 2013). En bloquant cette étape de la voie métabolique, l'herbicide induit une accumulation d'acide shikimique. Il en résulte, une diminution du taux de synthèse protéique et de la formation de certains composés phénoliques. La cessation de la croissance qui en découle est alors suivie de la nécrose des tissus qui aboutit à la mort de la plante (Kouassi Brou et al., 2012; PierreLouis, 2013).

Les semences des espèces annuelles telles que E. valerianifolia, $C$. bustamanta et E. sonchifolia sont restées dormantes dans le sol en conservant leur vitalité et le retour des conditions plus favorables a permis leur germination. La réapparition des espèces est aussi due au fait que le fluroxypyr stimule la croissance des cellules.

La persistance des pesticides est directement liée à leur dégradation. D'après une étude menée par Mamy et al. (2011), le glyphosate est l'herbicide pour lequel les risques de dispersion dans l'environnement sont les plus faibles (rétention élevée et faible persistance). Cependant, son produit de dégradation (l'AMPA) peut s'accumuler dans les sols et avoir un impact sur la «population humaine ». De plus, selon Darmency (2010), l'utilisation répétée du glyphosate pourrait conduire à des phénomènes de résistances des mauvaises herbes dont l'élimination serait problématique et qui pourrait entraîner une augmentation des doses d'application. En effet, le développement de stratégies de lutte contre les mauvaises herbes basées sur un ensemble plus large de techniques agronomiques paraît prometteur. De plus, lorsque le désherbage s'avère nécessaire, il faut tenir compte de la méthode à suivre et du facteur temps. Les jeunes plants sont évidemment plus fragiles et c'est à ce stade de leur développement que les activités de désherbage sont les plus efficaces.

\section{Conclusion}

L'effet des herbicides à base de glyphosate et fluroxypyr sur les adventices les plus fréquentes dans la culture de l'hévéa au Nord du Gabon a montré que le désherbage chimique en hévéaculture est primordial. En effet, l'étude a permis d'identifier les espèces 
les plus fréquentes sur les interlignes de l'hévéa et optimiser l'effet de deux herbicides à base de glyphosate et de fluroxypyr au cours des temps de fanaison, de jaunissement et de sénescences des adventices. Elle a révélé que ces différents temps ainsi que la rémanence des produits seraient influencés de façon différente, en fonction des espèces recensées au cours des relevées floristiques, des doses utilisées pour détruire les mauvaises herbes et du site d'application. En ce qui concerne les espèces, l'étude a prouvé que l'espèce Lippia citrata est la plus sensible aux traitements, tandis que la moins sensible est l'espèce Melastoma sp. S'agissant des doses utilisées, les meilleurs résultats ont été obtenus avec la combinaison de la forte dose soit du glyphosate ou du fluroxypyr (T12, T10 et T6) sur les temps de fanaison, de jaunissement et de sénescence. La rémanence est plus marquée avec l'utilisation des fortes doses de fluroxypyr quelle que soit la dose de glyphosate. Les deux produits étant des herbicides systémiques, seules quelques espèces ont pu réapparaître en fin de rémanence des produits. Les résultats actuels ne sont qu'une étape et représentent une avancée importante que l'entreprise pourrait transférer aux techniciens pour améliorer leurs méthodes de lutte contre les mauvaises herbes présentes sur les différents sites. Afin d'optimiser l'utilisation des produits herbicides, il est important de maîtriser la période de fanaison, de jaunissement et de sénescence des adventices ainsi que la rémanence des produits utilisés.

\section{CONFLITS D'INTERETS}

Les auteurs déclarent qu'il n'y a aucun conflit d'intérêts par rapport cet article.

\section{CONTRIBUTION DES AUTEURS}

L'auteur principal POO a conduit l'étude, collecté, traité les données et rédigé l'article. Les co-auteurs PKAO et SDMM ont contribué à la collecte des données sur le terrain. CK et JD ont lu et approuvé la version finale du manuscrit.

\section{REMERCIEMENTS}

Les auteurs remercient la Direction d'Olam Rubber pour avoir autorisé le déroulement de l'essai sur le site de Batouri et fourni des appuis techniques. Toute l'équipe du Laboratoire de Biologie Moléculaire et de Biotechnologie pour leurs contributions.

\section{REFERENCES}

Ada Olomo PK. 2014. Effet de deux herbicides base de glyphosate et fluroxypyr sur les espèces d'adventices les plus fréquentes dans la culture de l'hévéa (Hevea brasiliensis (H.B.K.) (Muell.Arg.) sur le site de Batouri, au Nord du Gabon. Mémoire de fin de cycle Ingénieur Agronome. Université des Sciences et Techniques de Masuku. INSAB/Franceville, p. 70.

Ahonon BA, Traoré A, Ipou IJ. 2018. Mauvaises herbes majeures de la culture de haricot ( Phasealus vulgaris L.) dans la région du Moronou au Centre-Est de la Côte d'Ivoire. Int. J. Biol. Chem. Sci., 12(1): 310-321. DOI : https://dx.doi.org/10.4314/ijbcs.v12i1.25

Akintayo I, Cisse B, Zadji LD. 2008. Guide pratique de la culture des NERICA de plateau. Centre du riz pour l'Afrique (ADRAO). 36p.

Amegnaglo KB, Dourma M, Akpavi S, Akodewou A, Wala K, Diwediga B, Atakpama W, Agbodan KML,Batawila K, Akpagana K. 2018. Caractérisation des formations végétales pâturées de la zone guinéenne du Togo: typologie, évaluation de la biomasse, diversité, valeur fourragère et régénération. Int. $J$. Biol. Chem. Sci., 12(5): 2065-2084. DOI:

https://dx.doi.orgg/10.4314/ijbcs.v12i5.9

Ayichedehou M. 2000. Phytosociologie, Ecologie et Biodiversité des phytocénoses culturales et post culturales du sud et du centre Benin. Thèse de Doctorat, Université libre de Bruxelles, Bruxelles, p. 282. 
Aubry C, Michel-Dounias I. 2006. Systèmes de cultures et décisions techniques dans l'exploitation agricole. In L'Agronomie Aujourd'hui, Doré T Le Bail M, Martin P, Ney B, Roger-Estrade J (eds). Editions Quae : Paris ; 57-75.

Bakayoko G, Kouassi C, Boraud MNK. 2016. Diversité floristique et importance agronomique des adventices des plantations d'igname de M'Bahiakro, Centre-Est de la Côte d'Ivoire. Afrique Science, 12 (6): 244-252.

Bello S, Ahanchede A, Gbehounou G, Amadji G, Aho N. 2013. Diversité floristique, ethnobotanique et taxonomie locale des mauvaises herbes de l'oignon au Nordest du Bénin. Tropicultura, 31(2) : 143152.

Bertonnier L, Bonansea V, Bonnet F, Durand R-C. 2012. Etude du glyphosate (Roundup). INP, Génie industriel, Grenoble, p3.

Boraud MNK. 2000. Etude floristique et phytoécologique des adventices des complexes sucriers de Ferké 1 et 2, de Borotoukoro et de Zuénoula, en Côte d'Ivoire. Thèse de Doctorat $3^{\text {ème }}$ cycle, Université de Cocody, Cocody, p. 184.

Boraud MNK, Aké-Assi E, N'Dja Kassi J, Aké S, Gasquez J. 2010. Impact agro écologique de simulation de culture transgénique de maïs résistant au glyphosate et effet répétitif d'un traitement herbicide sur la flore adventice en Côte d'ivoire. Sciences \& Nature, 7 (1): 41 - 49.

Boraud MNK : 2014. Cours de Malherbologie. USTM/INSAB, Franceville/Gabon. 70p.

Calvet R, Barruiso E, Benoit P, Bedos C, Charnay MP, Coquet Y. 2005. Les Pesticides dans le Sol. Conséquences Agronomiques et Environnementales. Editions France Agricole : Paris, p. 637.

CIRAD. 2001. Malherbologie tropicale. Centre de coopération internationale en recherche agronomique pour le développement, Informations légales $\odot$ Copyright Cirad 2001.

Daget Ph, Poissonet J. 1969. Analyse phytosociologique des prairies. Application agronomique. CNRS-CEPE. Document $\mathrm{N}^{\circ} 48$, p. 67.

Darmency H. 2010. Conséquences de l'utilisation des OGM sur l'usage des pesticides. Oléagineux, Corps gras, Lipides, 17 : 1-5.

Ekhator F, Ola OT, Ikuenobe CE. 2018. Effectiveness of tank mixture of glyphosate plus metsulfuron for weed control in a juvenile oil palm in Nigeria. Int. J. Agron. Agri. R., 13 (1): 29-38.

Hurrell GA, James TK, Lusk CS, Trolove M. 2008. Herbicide selection for wandering jew (Tradescantia fluminensis) control. Weeds natural ecosystem. New Zealand Plant Protection, 61: 368-373.

Kâ SL, Mbaye MS, Guèye M, Camara AA, Dieng B, Noba K. 2019. Flore adventice $\mathrm{du}$ sorgho (Sorghum bicolor (L.) Moench en Haute Casamance, zone soudanienne du Sénégal. Int. J. Chem. Sci., 13(1): 411-425. DOI https://dx.doi.org/10.4314/ijbcs.v12i1.25

Komba RM. 2013. Analyse comparative de l'efficacité de deux herbicides associés à différentes doses: cas du Round up et Ally en rond chimique sur le palmier à huile (Elaeis guineensis Jacq) à Olam palm Kango. Mémoire de fin de cycle Ingénieur Agronome, INSAB/USTM, Franceville/Gabon, 45 p.

Kouassi Brou G, Denezon Dogbo O, N'Zué B, Akhanovna J, Yves-Alain BrékoY. 2012. Effet du glyphosate sur la biosynthèse des constituants phénoliques de Manihot esculenta Crantz. Revue Internationale de génie électrique, $\mathbf{8}$ : 32-43.

Kouadio YP, Tiébré MS,Kouassi RH, Kassi NJ, N'Guessan K E. 2004. Limites du 
désherbage chimique en bananeraies industrielles de Dabou au Sud de la Côte d'Ivoire. American Journal of Scientific Research, 101: 64-67.

Laitinen P, Siimes K, Eronen L, Ramos S, Welling L, Oinonen S, Mattsoff L, Ruohonen-Lehto MR. 2006. Fate of the herbicides glyphosate, glufosinateammonium, phenmedipham, ethofumesate and metamitron in two Finnish arable soils. Pest Management Science, 62 :473-491.

Le Mer Ch, Roy R, Pellerin J, Maltais D. 2009. Effects of chronic exposures to the herbicides atrazine and glyphosate to larvae of the three-spined stickleback (Gasterosteus aculeatus). Université du Québec à Rimouski, Québec, Canada, p6.

Maillet J. 1981. Evolution de la flore adventice dans le Montpelliérain sous la pression des techniques culturales. Thèse de Docteur ingénieur, USTLMontpellier, Montpellier, p. 200.

Mamy L. 2001. Devenir des résidus de pesticides dans le sol dans les systèmes de culture employant des OGM résistants à ces molécules. Biosphère continentale : sols, écosystèmes, atmosphère. INRA Grignon, p30-32.

Mamy L, Barriuso E. 2005. Glyphosate absorption in soils compared to herbicides replaced with the introduction of glyphosate resistant crops. Chemosphore, 61: 844-855.

Mamy L, Barriuso E, Gabrielle B. 2008. Measurement and modelling of glyphosate fate compared to that of herbicides replaced as a result of the introduction of glyphosate-resistant oilseed rape. Pest Management Science, 64 : 262-275.

Mamy L, Barriuso E, Gabrielle B. 2011. Impacts sur l'environnement des herbicides utilisés dans les cultures génétiquement modifiées. Courrier de l'environnement de l'INRA, 60 : 15-24.

Mazzella N, Tran-Thi Nhu-T, Delest B. et Delmas F. 2009. Développement et validation d'une méthode permettant le dosage du glyphosate et de l'AMPA dans les eaux de surface par HPLC-ESIMS/MS, XXIXème congrès du groupe Français des Pesticides, Toulouse, France, $4 \mathrm{p}$.

Ndoutoumou Ndong A. 2007. Importance de l'association des clones d'hévéas dans l'amélioration de la production du caoutchouc en plantations industrielles au Gabon. Tropicultura, 25 : 66-69.

Ndotam Tatila IN, Reounodji F, Lumandé Kasali J, Diaouangana J. 2017. Evaluation de la diversité floristique en herbacées dans le Parc National de Manda au Tchad. Int. J. Biol. Chem. Sci., 11(4) : $\quad$ 1484-149. DOI: http://dx.doi.org/10.4314/ijbcs.v11i4.7.

Neuweiler R. 2009. Optimisation de la tolérance des cultures aux herbicides, Station de recherche Agroscope Changins-Wadenswil ACW, Département fédéral de l'économie. Confédération Suisse, Information Cultures Maraîchères $n^{\circ} 15,3 p$.

Ofosu-Budu KG, Avaala SA, Zutah VT, Baafi J. 2014. Effect of glyphosate on weed control and growth of oil palm at immature stage in Ghana. Int. J. Agron. Agri. R., 4 (4) : 1-8.

Olam Rubber Bitam: 2013. Coordonnées géographiques du site Batouri, Service Cartographie et Topographie d'Olam Bitam. p. 11.

Ondo Ovono P, Kebangoye HS, Medza Mve SD, Nguema Ndoutoumou P, Kevers C, Dommes J. 2018. Facteurs permettant d'améliorer la réussite au greffage des clones GT1 et PB217 d'Hevea brasiliensis (H.B.K.) (Muell. Arg) dans les conditions climatiques $\mathrm{du}$ nord 
Gabon. Journal of Animal and Plant Sciences, 35(3) : 5749-5762.

Ouattara D, Kouame D, Tiebre MS, Cisse A, N'Guessan KE. 2016. Diversité floristique et usages des plantes dans la zone soudanienne du Nord-ouest de la Côte d'Ivoire. Journal of Animal and Plant Sciences, 31 (1): 4815-4830.

Ouattara D, Kouame D, Tiebre MS, Kouadio YJC, N'Guessan KE. 2016. Biodiversité végétale et valeur d'usage en zone soudanienne de la Côte d'Ivoire. Int. J. Biol. Chem. Sci., 10(3): 1122-1138. DOI:

http://dx.doi.org/10.4314/ijbcsV10i3.18.

Pierre-Louis R. 2013. Evaluation des risques à long terme des herbicides à base de glyphosate sur la santé humaine, Thèse de doctorat, Université de Limoges, Limoges, p. 39-45.

Schrack D, Coquil X, Ortar A, Benoît M. 2009. Rémanence des pesticides dans les eaux issues de parcelles agricoles récemment converties à l'Agriculture Biologique. Innovations Agronomiques, p. 268.

Sylla M, Traoré K, Soro D, Yode TEG. 2017. Evaluation des pratiques de gestion des adventices en riziculture irriguée dans la localité de Daloa, centre-ouest de la Côte d'Ivoire. Agronomie Africaine, 29(1): 49-64.
Tchuemguia FNB. 2017. Etude comparative de l'effet de trois traitements herbicides (simples ou associés) sur la flore adventice du jardin à bois de greffe d'OlamRubber Gabon (Bitam/Batouri). Mémoire de fin de cycle Ingénieur Agronome. Université des Sciences et Techniques de Masuku. INSAB/Franceville, p. 72.

Tiébré MS, Ouattara D, Kpangui KB, Kouassi DF, N'Guessan KE. 2016. Diversité floristique de la région de Foungbesso en zone de transition forêt-savane à l'Ouest de Cote d'Ivoire. Int. J. Biol. Chem. Sci., 10(3): 1007-1016.

DOI:

http://dx.doi.org/10.314/ijbcs.v10i3.8.

Tissut M, Delval Ph, Mamarot J. et Ravanel P. 2006. Plantes, Herbicides et Désherbage. Association de coordination technique agricole : Paris Cedex.

Touré A, Ipou Ipou J, Adou Yao CY, Boraud MKN, N'Guessan KE. 2008. Diversité floristique et degré d'infestation des mauvaises herbes des agroécosystèmes environnant de la forêt classée de Sanaimbo, dans le Centre-Est de la Côte d'Ivoire. Agronomie Africaine, 20(1): 13-22. 